\title{
Socio-cognitive Factors and Perceived Barriers: Their Influence on the Patient's Adherence to Pulmonary Tuberculosis Treatment
}

\author{
Eleanor C. Castillo
}

Department of Health Promotion and Education, College of Public Health, University of the Philippines Manila

\begin{abstract}
Objectives. This descriptive-correlational study aims to determine the extent of socio-cognitive characteristics, perceived barriers and the factors contributing to treatment adherence among PTB patients.
\end{abstract}

Methods. A survey was administered to PTB patients registered under the Directly Observed Treatment Short Course (DOTS) program of Binan and Cabuyao, Laguna. Records review and key informant interview were also utilized to determine adherence rates.

Results. There were 184 PTB patients who participated in the study. Knowledge on PTB and its treatment and perceived threat of PTB was high, and perceived barriers to PTB treatment is low; but the respondents were uncertain on the perceived benefits of PTB treatment adherence. Perceived social support towards PTB treatment adherence was high, opportunity and time costs were low, and accessibility to PTB treatment services was high. Adherence to daily medication taking was reported by $98.4 \%$ of the respondents and $78.3 \%$ of these had the intention to complete the duration of PTB treatment. The level of knowledge on PTB and its treatment, and social support from the community, and treatment partners were the most significant predictors of PTB patients' adherence to treatment.

Conclusion. The adherence rate of the PTB patients to their treatment was high, and the extent of knowledge on PTB and its treatment was the greatest influencing factor towards PTB patients' adherence to treatment.

Key Words: adherence, pulmonary tuberculosis, barriers, sociocognitive factors

\section{Introduction}

Tuberculosis (TB) remained to be a major public health problem in the Philippines. It is the sixth leading cause of morbidity and mortality in the country, and the Philippines is ninth out of the 22 highest TB burden countries in the world. From 2003 to 2011, a total of 1,379,390 cases of TB of

Corresponding author: Eleanor Castillo, DrPH

Department of Health Promotion and Education

College of Public Health

University of the Philippines Manila

625 Pedro Gil Street, Ermita, Manila 1000 Philippines

Telephone: +6325260811

Email: annilovecastillo@yahoo.com all forms were diagnosed and given treatment, and of these cases, pulmonary tuberculosis (PTB) comprised $98.9 \%$ of all TB cases notified and extra-pulmonary TB made up the remaining $1.1 \%$. The number of new smear positive PTB cases increased by 34\% in 2011 compared to 2003. Furthermore, the Philippines has one of the highest burdens of multi-drug resistant $\mathrm{TB}$, which is greatly attributed to treatment non-adherence. ${ }^{1}$ Low cure rates in previous years (2008-2010) were mainly due to the high number of patients who completed treatment without laboratory confirmation of cure, and defaulting from treatment. These defaulters give rise to future drug-resistant cases. ${ }^{2}$

PTB however, is no longer a deadly disease like it was in the early $19^{\text {th }}$ century. With the advent of more potent combination of antibiotics, coupled with social and behavioral interventions to increase adherence, PTB is highly preventable and curable. To help cure people with PTB, the Directly Observed Treatment, Short course (DOTS) strategy is being implemented in many countries, the Philippines, included. DOTS strategy embodies low cost and a strong managerial approach using available technologies such as sputum microscopy and anti-PTB drugs, within the existing health system. This strategy includes the delivery of a standard short course of drugs, lasting six months for new patients and eight months for retreatment patients. Despite this, the World Health Organization estimated that only 58\% of the PTB patients in the Philippines adhere to treatment. ${ }^{3}$

The difficulty experienced by patients following a particular treatment regimen has raised awareness on adherence as a complex behavioral issue, influenced by many factors. Lack of a comprehensive and holistic understanding of barriers to and facilitators of treatment adherence is currently a major obstacle to finding effective solutions. Efforts to improve treatment outcomes require a better understanding of the particular barriers to, and facilitators of adherence to PTB treatment, and of patient experiences of taking treatment. ${ }^{4}$

One of the identified barriers to adherence to PTB treatment is stigmatization. Fear of infection, of infecting others, and of the serious social as well as economic consequences of TB stigma has increased TB diagnostic delay and treatment non-adherence. ${ }^{5}$

Social factors such as unemployment, migration, homelessness, older age and less education were found to be 
more likely associated to treatment non-adherence. In addition, cognitive factors, such as lack of knowledge on the transmission, risk factors and treatment of PTB is one of the major reasons for treatment non-adherence. Studies in India, Swaziland, Thailand and Zambia indicated that poor knowledge about the length of treatment, and misconceptions of well-being with cure leads to treatment default. Also, patients interrupt treatment as soon as they feel better around two months after initiating chemotherapy. ${ }^{6}$

Robust association between external constraints and treatment non-adherence has also been established. Distance from DOTS clinics, transportation costs and other financial and/or cost difficulties were cited as the major reasons for PTB treatment non-adherence. ${ }^{6}$

Despite the reported high non-adherence rates among PTB patients all throughout the country, some cities and municipalities in the Philippines have reported high adherence rates (above 90\%) among PTB patients enrolled in the DOTS program, Many of these cities and municipalities are located in urban or semi-urban areas.

In an effort to contribute towards higher treatment success, and prevention of further PTB infection among the population, this study was devoted to unraveling the factors influencing treatment adherence among the PTB patients in Binan and Cabuyao, Laguna. These factors will then be recommended to be embedded in the PTB prevention and control programs of cities and municipalities with low PTB treatment adherence rates.

\section{Objectives}

The purpose of this paper was to determine the influence of socio-cognitive characteristics and perceived treatment barriers to adherence of PTB patients to treatment. The specific objectives were:

- To determine the extent of socio-cognitive characteristics of the PTB patients in terms of their knowledge, beliefs, and social support related to PTB and treatment adherence;

- To determine the extent of perceived barriers to PTB treatment adherence among the PTB patients in terms of financial cost, opportunity cost, accessibility and side effects;

- To determine the extent of patient adherence to PTB treatment in terms of daily intake of medications, and intention to complete the recommended duration of treatment;

- To identify the factors that influence adherence to PTB treatment.

\section{Materials and Methods}

This study utilized the descriptive correlational design to determine the factors contributing to PTB treatment adherence among PTB patients who were enrolled in the
DOTS program of Binan and Cabuyao, Laguna City Health Offices in 2010, which were chosen as study sites because of the reported high patient adherence to PTB treatment for three consecutive years (2007-2009).

The study protocol was subjected to technical review by a five-member panel of the Adventist University of the Philippines (AUP), and ethical review by the Graduate Council of the same university.

To identify the respondents of the study, purposive sampling was utilized, where the inclusion criteria were as follows: (a) 18 - 90 years old, (b) resident of Binan or Cabuyao, Laguna, and (c) enrolled in the National TB Program - DOTS course in Binan or Cabuyao, Laguna. PTB patients who are not enrolled in the National TB Program DOTS course were not recruited as study respondents.

In order to gather the data, the researcher sought the permission of the City Health Officers (CHOs) on both study sites to conduct the study. A written letter of request and a copy of the proposal was submitted to the CHOs for review. Approval was granted and the $\mathrm{CHOs}$ provided the researcher a list of all the PTB patients enrolled in their DOTS program. The researcher oriented and enlisted the assistance of the Barangay Health Workers (BHWs) for data gathering.

Based on the 2010 National Tuberculosis Program (NTP)-DOTS records, there were 88 PTB patients enrolled in the DOTS program in Cabuyao, while there were 98 in Binan. All of the 88 PTB patients in Cabuyao participated in the study, but only 96 in Binan (two patients could not be located at the time of data gathering), giving a total of 184 respondents.

A self-administered questionnaire was primarily used as a tool to gather data. Data collection was conducted in the health centers as the PTB patients returned to the health centers for their weekly supply of medications, and in the patients' homes in some cases where the PTB patients failed to report to the health centers for their return visits. Key informant interviews among the City Health Officers, records review of the adherence rates in the past three years and non-participant observation, particularly of the health education strategies and materials in the health centers, were also employed to gather possible data that would explain or further elucidate research results.

To protect the identity of the PTB patients, since being diagnosed with PTB may cause social stigmatization, the PTB patients were anonymized by assigning code numbers for each of them. Only the code numbers were reflected in the survey questionnaire. Furthermore, before the PTB patients were asked to participate in the study, the purposes and objectives of the study were explained to them. It was made clear to the PTB patients that participation to the study is not a prerequisite for their access to their PTB medications, and other services offered by the health center. Then, the respondents were asked to sign the informed consent form, 
after they were given time to read and the opportunity to ask questions.

The instrument was a self-constructed questionnaire which was subjected to expert validation and pilot testing. A reliability coefficient of 0.70 and higher for each construct was obtained. The questionnaire had six parts: (1) demographic characteristics such as age, gender, educational attainment, main occupation, personal average monthly income and length of stay in current residence; (2) cognitive characteristics in terms of level of knowledge on PTB transmission, signs and symptoms, causes and risk factors and treatment and cure; (3) social characteristics such as beliefs about PTB and treatment adherence, (4) perceived social support derived from the family members, treatment partners and community; (5) perceived barriers to treatment including cost of treatment, accessibility of PTB treatment services, and extent of side effects; and (6) adherence to PTB treatment using extent of daily intake of PTB medications, and intention to continue adhering to the treatment until its completion.

True or false questions were used to determine the level of knowledge of the respondents on PTB and treatment adherence. The percentage of correct answers for each question was determined, and the total knowledge score was also computed. The perfect knowledge score was 29 points, and the scores of the respondents were classified as follows: $0-10=$ low; $11-20=$ average; and $21-29=$ high. To measure beliefs (on perceived threat and benefits) and social support related to PTB treatment adherence, the mean for the subscale responses were interpreted as: $1.0-1.50=$ disagree, $1.51-2.50=$ uncertain, and $2.51-3.00=$ agree. Overall mean score for beliefs and social support were interpreted using the following classification: $1.0-1.50=$ low; $1.51-2.50=$ average; and $2.51-3.00=$ high .

Scoring system for the barriers to PTB treatment adherence is presented in Table 1.

Table 1. Scoring System of Barriers to PTB Treatment

\begin{tabular}{lll}
\hline \multicolumn{1}{c}{ Variable } & Score & Verbal Interpretation \\
\hline Financial Cost & $1.00-1.50$ & Free \\
& $1.51-2.50$ & Low \\
& $2.51-3.50$ & Just right \\
& $3.51-4.00$ & High \\
Opportunity/Time Cost & $1.00-1.50$ & Low \\
& $1.51-2.50$ & Uncertain \\
Accessibility & $2.51-3.00$ & High \\
& $1.00-1.50$ & Low \\
Side Effects & $1.51-2.50$ & Uncertain \\
& $2.51-3.00$ & High \\
& $1.00-1.50$ & Low \\
& $1.51-2.50$ & Uncertain \\
& $2.51-3.00$ & High \\
\hline
\end{tabular}

The data was encoded using the Statistical Package for Social Sciences (SPSS) version 11 software. As to the statistical treatment, mean, standard deviation and percentage were employed to determine the extent of the respondents' demographic, social, and cognitive characteristics, and the extent of perceived barriers to PTB treatment adherence. Frequency distribution and percentage were used to determine the extent of patient adherence in terms of daily medication taking and intention to complete the treatment. Multiple linear regression analysis was applied to identify the factors that influence the respondents' adherence to PTB treatment.

\section{Results}

There were 184 respondents in this study. The mean age was 42 years, a little more than half (62.5\%) are male, $40 \%$ had an elementary education, while $50.5 \%$ had a secondary education. More than half (58.2\%) are unemployed, while the other $41.2 \%$ were engaged in blue collar jobs such as car wash, garbage collection, carpentry, construction work, tricycle driving and farming. Eightyseven percent reported a monthly income of less than $\mathrm{P} 4,000.00$, and $71.7 \%$ have been staying in their current place of residence for more than five years. The respondents of the study have been enrolled with the DOTS program for an average of 2-4 months.

As presented in Table 2, the knowledge of the respondents in terms of PTB transmission, causes and/or risk factors, signs and symptoms and treatment or cure were high, as in most cases, more than $95 \%$ of the respondents answered correctly the true or false questions.

In terms of PTB transmission, more than 95\% knew that PTB is contagious and it could be transmitted through one's breath or by sneezing. It could be noted however, that there are prevailing misconceptions regarding PTB. For example, $21.4 \%$ answered false to the statement "PTB is transmitted by talking and laughing", and $24.5 \%$ answered true to the statement "PTB is transmitted by shaking hands", and $96.7 \%$ of the respondents answered true to the statement" PTB is transmitted by sharing eating utensils with a PTB patient".

More than $95 \%$ of the respondents are aware that malnutrition, dirty environment and lack of immunization increase the chances of acquiring PTB, however, $8 \%$ of the respondents think that poor personal hygiene and overcrowding do not increase the risk of PTB. More importantly, about $25 \%$ of the respondents have a misconception that changes in climate or weather increases the risk for PTB.

Knowledge on the signs and symptoms of PTB was high among the respondents, as more than $95 \%$ of them gave correct answers to questions related to this topic. When it comes to their knowledge on the appropriate treatment or cure for PTB, although more than $95 \%$ of the respondents are aware that completion of a 6-month treatment period is needed, and that taking antibiotics not prescribed by their doctor is not recommended, it is alarming that the following misconceptions prevail among the respondents: (a) TB can 
be cured by taking herbal medications (8.2\%) and vitamin supplements (21.1\%); (b) when signs and symptoms of PTB subside, the patient can stop taking drugs (29.3\%), and (3)a person who has completed the recommended TB treatment will no longer have PTB in the future $(9.8 \%)$.

Table 2. Knowledge on PTB (N -=184)

\begin{tabular}{|c|c|c|}
\hline \multirow{2}{*}{$\begin{array}{l}\text { Knowledge on: } \\
\text { PTB Transmission }\end{array}$} & \multicolumn{2}{|c|}{ Correct answer } \\
\hline & Frequency & Percent \\
\hline - Tuberculosis is transmitted through one's breath & 176 & 95.7 \\
\hline - Tuberculosis is transmitted by talking or laughing & 163 & 88.6 \\
\hline $\begin{array}{l}\text { - Tuberculosis is transmitted through shaking of } \\
\text { hands }\end{array}$ & 139 & 75.5 \\
\hline $\begin{array}{l}\text { - Tuberculosis is transmitted through sneezing, not } \\
\text { covering one's nose }\end{array}$ & 181 & 98.4 \\
\hline $\begin{array}{l}\text { - Tuberculosis is transmitted through sharing of } \\
\text { eating utensils with TB patient }\end{array}$ & 178 & 3.3 \\
\hline - Tuberculosis is not contagious & 180 & 97.8 \\
\hline \multicolumn{3}{|l|}{ Cause or Risk Factors of PTB } \\
\hline $\begin{array}{l}\text { - The following factors increase the risk of PTB } \\
\text { infection-malnutrition }\end{array}$ & 181 & 98.4 \\
\hline $\begin{array}{l}\text { - The following factors increase the risk of PTB } \\
\text { infection - good personal hygiene }\end{array}$ & 171 & 92.9 \\
\hline $\begin{array}{l}\text { - The following factors increase the risk of PTB } \\
\text { infection-overcrowding }\end{array}$ & 168 & 91.3 \\
\hline $\begin{array}{l}\text { - The following factors increase the risk of PTB } \\
\text { infection - dirty environment }\end{array}$ & 182 & 98.9 \\
\hline $\begin{array}{l}\text { - The following factors increase the risk of PTB } \\
\text { infection - immunization }\end{array}$ & 178 & 96.7 \\
\hline $\begin{array}{l}\text { - When side effects from drugs are experienced, I } \\
\text { should stop taking drugs }\end{array}$ & 154 & 83.7 \\
\hline - Untreated tuberculosis can cause death & 181 & 98.4 \\
\hline - Tuberculosis is caused by climatic changes & 139 & 75.5 \\
\hline \multicolumn{3}{|l|}{ Signs and Symptoms of PTB } \\
\hline $\begin{array}{l}\text { The following are signs and symptoms of PTB- } \\
\text { cough for more than two weeks }\end{array}$ & 181 & 98.4 \\
\hline $\begin{array}{l}\text { - The following are signs and symptoms of PTB - } \\
\text { afternoon or night fever }\end{array}$ & 180 & 97.8 \\
\hline $\begin{array}{l}\text { - The following are signs and symptoms of PTB - } \\
\text { backache or pain }\end{array}$ & 183 & 99.5 \\
\hline $\begin{array}{l}\text { - The following are signs and symptoms of PTB - } \\
\text { weight gain }\end{array}$ & 183 & 99.5 \\
\hline $\begin{array}{l}\text { - The following are signs and symptoms of PTB - } \\
\text { lack of or poor appetite }\end{array}$ & 179 & 97.3 \\
\hline $\begin{array}{l}\text { - The following are signs and symptoms of PTB - } \\
\text { coughing out of blood }\end{array}$ & 179 & 97.3 \\
\hline \multicolumn{3}{|l|}{ Treatment or Cure of PTB } \\
\hline - Tuberculosis cannot be cured & 182 & 98.9 \\
\hline $\begin{array}{l}\text { - Non-adherence to PTB treatment increases the } \\
\text { chance for developing resistance to other antibiotics }\end{array}$ & 175 & 95.1 \\
\hline $\begin{array}{l}\text { - Tuberculosis can be cured eventually even without } \\
\text { taking anti-TB medications }\end{array}$ & 182 & 98.9 \\
\hline $\begin{array}{l}\text { - Tuberculosis can be cured by taking - herbal } \\
\text { medicines }\end{array}$ & 169 & 91.8 \\
\hline $\begin{array}{l}\text { Tuberculosis can e cured by taking - vitamin } \\
\text { supplements }\end{array}$ & 147 & 79.9 \\
\hline $\begin{array}{l}\text { Tuberculosis can be cured by taking - antibiotics } \\
\text { not recommended by a doctor }\end{array}$ & 175 & 95.1 \\
\hline $\begin{array}{l}\text {-Wen signs and symptoms related to PTB subside, } \\
\text { the patient can stop taking drugs }\end{array}$ & 130 & 70.7 \\
\hline $\begin{array}{l}\text { - In order to cure a person with } \mathrm{TB} \text {, completion of a } 6 \\
\text { month treatment is needed }\end{array}$ & 176 & 95.7 \\
\hline $\begin{array}{l}\text { - A person who has completed the recommended TB } \\
\text { treatment will no longer have tuberculosis in the } \\
\text { future }\end{array}$ & 166 & 90.2 \\
\hline
\end{tabular}

In order to determine the level of knowledge of the respondents on $\mathrm{PTB}$, the total knowledge score of each respondent was computed and classified as follows: 1-10 = low, 11-20 = average, and 21-29 =high. The perfect score was 29 points. Results presented in Table 3 show that of the 184 respondents, 181 (98.5\%) got scores ranging from 22 to 29 points, and of these, 65 respondents (35.3\%) got a perfect score of 29 points. The mean score was 26.95

Table 3. Knowledge Score of the Respondents $(\mathrm{N}=184)$

\begin{tabular}{cccc}
\hline Knowledge Score & Frequency & Percent & VI \\
\hline 9.00 & 1 & .5 & Low \\
16.00 & 1 & .5 & Average \\
20.00 & 1 & .5 & Average \\
22.00 & 3 & 1.6 & High \\
23.00 & 8 & 4.3 & High \\
24.00 & 15 & 8.2 & High \\
25.00 & 10 & 5.4 & High \\
26.00 & 12 & 6.5 & High \\
27.00 & 47 & 25.5 & High \\
28.00 & 21 & 11.4 & High \\
29.00 & 65 & 35.3 & High \\
\hline
\end{tabular}

Beliefs on the threat of complications due to PTB was high (over-all mean $=2.55, \mathrm{SD}=.259$ ), while the respondents were uncertain (over-all mean $=2.04, \mathrm{SD}=.184$ ) on the benefits they would derive from PTB treatment adherence.

Perceived social support provided to the respondents by the family members, treatment partners and the community was measured using a 3-point Likert scale, with one being the lowest and 3 being the highest. As presented in Table 4, social support from the family members (as indicated by providing financial assistance, reminders for their treatment appointments, provision of additional information on PTB prevention, control and treatment, as well as social and moral support) was perceived to be high $($ mean $=2.87, \mathrm{SD}=0.26)$. Perceived social support from the respondents' treatment partners (in terms of providing reminders for follow-up appointments, informing them of the sputum and chest x-ray results, and providing motivation to adhere to their PTB treatment) such as the barangay health workers, and the midwives were also high, with a mean of $2.83, \mathrm{SD}=0.25$.

Perceived social support from the community where the respondents reside was indicated by the availability of sufficient health services for PTB prevention and control as well as social acceptability of the respondents despite their disease. Community is being referred to as their neighbors, community organizations, and the barangay leaders. Results showed that the social support of the community in relation to PTB treatment adherence was also high (mean $=2.85$, $\mathrm{SD}=0.32$ ). The highest level of perceived social support was derived from the respondents' family members, second from the community and third, from their treatment partners. Over-all perceived social support from the family, treatment partners and community was high. 
Table 4. Extent of Social Support $(\mathrm{N}=184)$

\begin{tabular}{lccc}
\hline & Mean & Std. Deviation & VI \\
\hline Social support-family & 2.87 & 0.26 & High \\
Social support-treatment partner & 2.83 & 0.25 & High \\
Social support-community & 2.85 & 0.32 & High \\
Social support & 2.85 & 0.18 & High \\
\hline
\end{tabular}

The financial cost is not perceived as a barrier for PTB treatment adherence as the respondents reported that they can avail of PTB medications and sputum tests from the health center for free, and that the cost of transportation from their house to the health center was low (Table 5).

Table 5. Financial Cost of PTB Treatment $(\mathrm{N}=184)$

\begin{tabular}{|c|c|c|c|}
\hline & Mean & $\begin{array}{c}\text { Std. } \\
\text { Deviation }\end{array}$ & $\begin{array}{c}\text { Verbal } \\
\text { Interpretation }\end{array}$ \\
\hline 1. TB medications & 1.01 & 0.10 & Free \\
\hline 2. Sputum test & 1.32 & 0.43 & Free \\
\hline $\begin{array}{l}\text { 3. Transportation from house } \\
\text { to health center }\end{array}$ & 1.73 & 0.68 & Low \\
\hline MEAN & 1.32 & 0.29 & Free \\
\hline
\end{tabular}

As presented in Table 6, opportunity and time costs were also perceived to be low, as the respondents agreed that the waiting time for services at the health center and travel time from their house to the health center was not long. They, however, were uncertain whether they missed important appointments, work or employment opportunities due to PTB treatment adherence.

Table 6. Opportunity and Time Costs of PTB ( $\mathrm{N}=184)$

\begin{tabular}{lccc}
\hline & Mean & $\begin{array}{c}\text { Std. } \\
\text { Deviation }\end{array}$ & $\begin{array}{c}\text { Verbal } \\
\text { Interpretation }\end{array}$ \\
\hline $\begin{array}{l}\text { I often miss important } \\
\text { appointments due to my TB } \\
\text { treatment schedules. }\end{array}$ & 1.65 & 0.90 & uncertain \\
$\begin{array}{l}\text { I cannot work regularly at home } \\
\text { because I have to go to the }\end{array}$ & 1.51 & 0.83 & uncertain \\
$\begin{array}{l}\text { health center for my } \\
\text { medications. }\end{array}$ & & & \\
$\begin{array}{l}\text { It does not take a long time to } \\
\text { wait for the TB treatment } \\
\text { services at the health center. }\end{array}$ & 1.27 & 0.65 & Agree \\
$\begin{array}{l}\text { Travelling from my house to the } \\
\text { health center does not take } \\
\text { much time. }\end{array}$ & 1.30 & 0.67 & Agree \\
$\begin{array}{l}\text { I have to give up opportunities } \\
\text { of employment due to my visits } \\
\text { to the health center for TB } \\
\text { treatment. }\end{array}$ & 1.67 & 0.91 & Uncertain \\
MEAN & & & \\
\hline
\end{tabular}

PTB treatment services were also perceived to be highly accessible and available to the respondents, as the respondents' houses were located near the health center, drug supply was adequate and regular, and it was not difficult to get an appointment with the physician. The respondents also agreed that the health services for PTB treatment were accessible, available and affordable, but were uncertain on the availability of chest x-ray machines and services in the health center (Table 7).

Table 7. Accessibility of PTB Treatment $(\mathrm{N}=184)$

\begin{tabular}{|c|c|c|c|}
\hline & Mean & $\begin{array}{c}\text { Std. } \\
\text { Deviation }\end{array}$ & $\begin{array}{c}\text { Verbal } \\
\text { Interpretation }\end{array}$ \\
\hline $\begin{array}{l}\text { My house is less than } 500 \text { meters } \\
\text { from the health center where I } \\
\text { get TB treatment services. }\end{array}$ & 2.65 & 0.66 & Agree \\
\hline $\begin{array}{l}\text { There is regular supply of TB } \\
\text { medicines in our health center }\end{array}$ & 2.91 & 0.35 & Agree \\
\hline $\begin{array}{l}\text { The supply of TB medicines are } \\
\text { adequate. }\end{array}$ & 2.91 & 0.32 & Agree \\
\hline $\begin{array}{l}\text { Chest } x \text {-ray machines and } \\
\text { services are available our health } \\
\text { center. }\end{array}$ & 2.40 & 0.86 & Uncertain \\
\hline $\begin{array}{l}\text { There is a laboratory for sputum } \\
\text { examination in our health center. }\end{array}$ & 2.88 & 0.43 & Agree \\
\hline $\begin{array}{l}\text { It is not difficult to get an } \\
\text { appointment with our physician } \\
\text { at the health center. }\end{array}$ & 2.80 & 0.54 & Agree \\
\hline $\begin{array}{l}\text { The health services for TB } \\
\text { treatment in our health center is } \\
\text { accessible }\end{array}$ & 2.86 & 0.49 & Agree \\
\hline $\begin{array}{l}\text { The health services for TB } \\
\text { treatment in our health center is } \\
\text { available }\end{array}$ & 2.76 & 0.58 & Agree \\
\hline $\begin{array}{l}\text { The health services for TB } \\
\text { treatment in our health center is } \\
\text { affordable }\end{array}$ & 2.77 & 0.58 & Agree \\
\hline MEAN & 2.77 & 0.27 & High \\
\hline
\end{tabular}

Side effects of medications was not perceived as a barrier to adherence as the respondents disagreed that they experienced increased sensitivity to the sun or reduced hearing, and were uncertain if they experienced other side effects related to PTB medications (Table 8).

Table 8. Extent of Side Effects of PTB Medications ( $\mathrm{N}=184)$

\begin{tabular}{lccc}
\hline Common Side Effects & Mean & $\begin{array}{c}\text { Std. } \\
\text { Deviation }\end{array}$ & $\begin{array}{c}\text { Verbal } \\
\text { Interpretation }\end{array}$ \\
\hline Increased sensitivity to the sun & 1.31 & 0.71 & Disagree \\
Reduced hearing & 1.48 & 0.84 & Disagree \\
Skin irritations, allergies, or rashes & 1.53 & 0.88 & Uncertain \\
Yellowish skin & 1.70 & 0.92 & Uncertain \\
Joint pains & 1.86 & 0.99 & Uncertain \\
Upset stomach & 1.82 & 0.96 & Uncertain \\
MEAN & 1.62 & 0.53 & Average \\
\hline
\end{tabular}

In summary, perceived barriers to PTB treatment adherence were low as the respondents did not have to pay for their PTB medications, did not incur significant opportunity and time losses as they availed of the PTB treatment, experiences of medication side effects were regarded as average, and health services for PTB treatment were highly available, accessible, affordable.

This study considered daily medication intake as the direct indicator for treatment adherence, while intention to continue or adhere to PTB treatment was the indirect 
indicator of treatment adherence. Results presented in Table 9 show that adherence to PTB treatment among the respondents who were enrolled in the DOTS program was high, as $98.4 \%$ reported taking their anti-PTB medications daily, with only three who were non-adherent to the recommended daily intake of medications. Results also showed that $86.4 \%$ of the respondents intend to complete the whole duration of PTB treatment.

Table 9. Adherence to PTB Treatment ( $\mathrm{N}=184)$

\begin{tabular}{lrr}
\hline \multicolumn{1}{c}{ Adherence to PTB Treatment } & Frequency & Percent \\
\hline \multicolumn{1}{c}{ Frequency of Anti-PTB Medication Intake } & & \\
3-4 times a week & 1 & 0.5 \\
5-6 times a week & 2 & 1.1 \\
Everyday & 181 & 98.4 \\
Total & 184 & 100.0 \\
$\quad$ Intention to Adhere to PTB Treatment & & \\
None & 17 & 4.3 \\
It depends on the result & 159 & 9.2 \\
Yes & 184 & 86.5 \\
Total & & 100.0 \\
\hline
\end{tabular}

Table 10 presents the factors influencing the respondents' adherence to PTB treatment. The respondents' high adherence to PTB treatment in terms of daily intake of medications was found to be influenced by the respondents' level of knowledge ( $\mathrm{t}$-value $=6.939$, $\mathrm{p}$-value $=.000$ ) and perceived social support from the community ( $\mathrm{t}$-value $=$ 2.419 , p-value $=.017$ ), which contributed $21.1 \%$ and $2.5 \%$, respectively, to the total variance in the daily intake of medications. The odds ratio (OR) for knowledge was 3.15, indicating that respondents with high level of knowledge were three times more likely to take their medications daily. The OR corresponding to perceived social support from the community was 1.52, implying that respondents who perceived higher community support in their PTB treatment as indicated by the community's social acceptance despite their condition were more likely to adhere to daily medication taking. Based on these results, the regression for frequency of taking anti-PTB medications daily is:

$\mathrm{y}=2.985+.028$ PTB knowledge +.083 social support from community

\section{Discussion}

Results on the knowledge level of the respondents on PTB was encouraging, as it showed that the respondents in general are highly aware of the risk factors, mode of transmission, signs and symptoms as well as treatment and cure for PTB. However, misconceptions related to the transmissibility of PTB through hand shake and sharing of utensils prevail, and not through talking or laughing. According to the Center for Disease Control, ${ }^{7}$ PTB is not spread by shaking someone's hand, sharing eating utensils or even toothbrushes and kissing. PTB is spread through the air from one person to another, specifically, the TB bacteria are out into the air when a person with TB coughs, sneezes, laughs or sings, and people nearby may breathe in these bacteria and become infected.

Some respondents are not aware that poor personal hygiene, overcrowding and lack of immunization against TB increases a person's risk for PTB infection. Knowledge of the respondents on PTB treatment and cure is lowest compared to the previous areas. More respondents have misconceptions that taking vitamins and herbal preparations cure PTB, and that a person who has completed PTB treatment can no longer be infected in the future. More importantly, about more than a quarter of the respondents have the misconception that when the signs and symptoms of PTB have subsided, they can stop taking their medications.

The above mentioned misconceptions have to be addressed as these would lead to improper PTB prevention and control practices. Non-adherence to PTB treatment regimen has been associated with misconceptions especially on quitting taking the daily medications when the signs and symptoms of PTB subside. These areas of PTB knowledge have to be addressed in the health education and promotion initiatives of the health centers. By educating patients with PTB and removing their misconceptions, adherence to treatment is likely to improve. ${ }^{8}$

The results of this current study is contrary to the previous findings of Portero, Yuste and Pasicatan ${ }^{9}$ which found that the level of general knowledge about TB in Metro Manila, Philippines was low (3.64 ${ }_{-}^{+} 1.67$, range 0-10). Studies done in Kenya ${ }^{10}$ and in Pakistan ${ }^{11}$ also revealed low levels of knowledge on PTB prevention and control both in the general population and among the PTB patients. Misconceptions regarding transmission of PTB, as well as its treatment and cure, particularly on non-completion of the treatment regimen as the occurrence signs and symptoms subside, were also common.

Interview with the city health personnel involved in the National Tuberculosis Program of Binan and Cabuyao, Laguna, including their City Health Officers, revealed that

Table 10. Predictors of Daily Intake of PTB Medications

\begin{tabular}{|c|c|c|c|c|c|c|c|c|c|c|}
\hline \multirow[t]{2}{*}{ Model } & \multirow[t]{2}{*}{$\mathbf{R}$} & \multirow[t]{2}{*}{$\mathbf{R}^{2}$} & \multirow[t]{2}{*}{ Adj. $R^{2}$} & \multirow[t]{2}{*}{$\mathbf{R}^{2}$ change } & \multicolumn{2}{|c|}{$\begin{array}{l}\text { Unstandardized } \\
\text { Coefficient }\end{array}$} & \multirow{2}{*}{$\begin{array}{c}\text { Standardized } \\
\text { Coefficient } \\
\text { Beta }\end{array}$} & \multirow[t]{2}{*}{$\begin{array}{l}\text { Odds } \\
\text { Ratio }\end{array}$} & \multirow[t]{2}{*}{$\mathrm{t}$-value } & \multirow[t]{2}{*}{ p-value } \\
\hline & & & & & Beta & SE & & & & \\
\hline Constant & & & & & 2.985 & .140 & & & 21.358 & .000 \\
\hline PTB Knowledge & .459 & .211 & .207 & .211 & .028 & .004 & .433 & 3.15 & .6542 & .000 \\
\hline Social Support from Community & .486 & .236 & .227 & .025 & .083 & .034 & .160 & 1.52 & 2.419 & .017 \\
\hline
\end{tabular}


their health personnel regularly conduct health education campaigns among the PTB patients and their family members during the consultation days of the PTB patients, which is every Thursday and Friday. Leaflets were also given out during these sessions, and reminders were given by the treatment partners, and barangay health workers whenever they would visit their patients.

It was also observed that the health centers in Binan and Cabuyao, Laguna have a health education corner, specifically allotted for PTB information. This health education corner was located near the waiting area for the PTB patients. The researcher observed that information on the nature of $\mathrm{TB}$, its mode of transmission, signs and symptoms, possible complications, and mode of treatment were displayed. These factors may have contributed to the high level of cognition on $\mathrm{TB}$ and its treatment among the respondents.

It is noteworthy that the respondents have high perceived threat from PTB complications, however, in general, they were uncertain as to the benefits of PTB treatment adherence. According to the Health Belief Model, ${ }^{12}$ perceived threat of a disease comes from the combined effects of perceived personal susceptibility to the disease and the perceived severity of the disease are significant factors influencing a behavior. Higher perceived threat of the complications brought about by PTB, as well as the possibility of their family members from being infected could enhance a PTB patient's resolve to adhere to PTB treatment.

Likewise, beliefs about the efficacy of treatment have an impact on adherence. In this study, the respondents were uncertain as to the benefits they would get from PTB treatment adherence, which indicate that the respondents are not yet fully convinced that adherence to PTB treatment can reduce their risk of having complications and/or dying from PTB, or reduce their chances of infecting other people. This uncertain belief on the efficacy of PTB treatment is related to patient confidence that PTB could be cured. Lack of confidence on the efficacy of PTB treatment is one risk factor for non-adherence. ${ }^{6}$

The respondents in this study receive high financial, informational, and moral support from their family members; coupled with informational and structural support from the health providers and the health centers; as well as social acceptability by the community members. Presence of these factors are indicative of low level of social stigmatization by these three segments of society for the PTB patients, which is a social determinant for increased adherence to PTB treatment.

Stigmatization is a complex process involving institutions, communities, inter-and intrapersonal attitudes, and has been recognized as an important social determinant of health and health-care seeking behaviors. It is a widely held view that $\mathrm{TB}$ stigma contributes to delays in $\mathrm{TB}$ diagnosis and negatively impacts treatment adherence. Individuals with TB identified TB stigma as a cause for noncompletion of treatment. On the other hand, low levels of stigmatization or social rejection as indicated by high social support and acceptance for PTB patients predict earlier diagnosis and better adherence to TB treatment regimen. ${ }^{13}$

In this study, barriers to treatment adherence such as financial cost, opportunity and time cost is low. However, PTB patients in other developing countries often identified the cost of treatment as a reason for treatment interruption. In some settings, patients reported that drugs were expensive, and where treatment itself was free, hidden costs such as hospital stays, reviews of x-ray results, and transport costs could be high. ${ }^{14}$

The respondents' uncertainty whether they experienced side effects of the PTB medications was an indication of uncommon side effects. These side effects, such as increased sensitivity to the sun, reduced hearing ability, skin irritations, allergies or rashes, and upset stomach, among others were found to be commonly experienced. Fong ${ }^{15}$ and Wares ${ }^{16}$ found that at least $60 \%$ of their respondents reported experiencing side effects to PTB medications such as reduced hearing, yellowish skin and upset stomach.

The results on the extent of socio-cognitive factors and perceived barriers to PTB treatment adherence indicate that the predisposing factors such as their knowledge and beliefs on the threats, benefits and barriers related to PTB, the reinforcing factors such as the high level of support from the family members, treatment partners and community, and enabling factors such as availability, accessibility and affordability of PTB treatment services were all in place. According to the PRECEDE model by Lawrence Green, ${ }^{17}$ these factors directly influence the behavior of a person, and the presence of these factors would encourage practice of healthy behaviors, which in this study is their adherence to PTB treatment.

The adherence rate to daily medication taking among the respondents of this study is high (98.4\%) when compared to the $90 \%$ target set by the Department of Health ${ }^{1}$ for 2010 . From the $98.4 \%$ of the 184 respondents who reported taking their medications daily, only 144 (78.3\%) admitted having the intention to complete the PTB treatment, the other respondents stated that their intention to complete the PTB treatment depends on the day to day results such as presence of side effects of the medication, and their general whole being. If the signs and symptoms of the disease subside, then the medications perceived as effective, and they will continue taking their medications. This result point out the need for continuous assessment of the PTB patients' adherence to treatment, the reasons for declining adherence, and the implementation of strategies in order to sustain adherence to PTB treatment.

The results of this study on the predictors of adherence to PTB treatment such as the level of knowledge and social 
support from the community is supportive of the results of previous studied. A study on factors associated to default from treatment among TB patients in Kenya ${ }^{10}$ concluded that high level of appropriate knowledge is a significant predictor of PTB treatment compliance, as it increases the PTB patients perceived susceptibility and vulnerability to the disease, as well as their understanding that PTB is curable, and the benefits derived from adherence to treatment. Social support from the community on the other hand reflects social acceptance which reduces the barriers caused by social rejection and stigmatization in treatment adherence. $^{13}$

Furthermore, the $\mathrm{WHO}^{5}$ affirmed that knowledge and social support are among the significant predictors of treatment adherence among PTB patients when it stated that "the following strategies were found to improve treatment adherence among pulmonary smear positive patients: (a) increase in the visibility of PTB programs in the community; (b) provide more information about the disease and treatment to patients and communities; (c) increase support from family, peers, and social networks; (d) minimize cost and unpleasantness related to clinic visits and increase flexibility and patient autonomy; (e) increase patient centeredness of interactions between providers and clients, (f) address "structural" and "personal" factors, for example through micro financing and other empowerment initiatives; and $(\mathrm{g})$ provide more information about the effects of medication".

\section{Summary and Recommendations}

The socio-cognitive characteristics of the respondents such as their level of knowledge, beliefs, social support related to PTB and treatment adherence were high; and the perceived barriers towards PTB treatment adherence were low. With these factors in place, the adherence to PTB treatment as indicated by daily medication intake and intention to adhere to PTB medication for the whole treatment duration, which was $98.4 \%$ and $78.3 \%$, respectively, was high. The respondents' extent of knowledge on PTB and its treatment, as well as extent of perceived social support from family, community, and treatment partners exert the greatest influence on their adherence to PTB treatment.

As an offshoot of this study, the following are recommended:

- That health care providers in-charge of the DOTS program in health centers continually update their patients about PTB as a disease, and PTB treatment adherence. Emphasis should be given on the proven benefits of PTB treatment adherence, the appropriate treatment regimen for PTB and the consequences of defaulting or non-adherence to PTB treatment.
- Support groups for PTB patients consisting of family members, peers, treatment partners and community volunteers should be organized, and involved in the PTB prevention and control campaigns.

- Good practices of the cities of Binan and Cabuyao on how to enhance patient adherence to PTB treatment be documented, and the lessons learned from these two cities be disseminated to other municipalities or cities.

\section{Acknowledgment}

The author would like to thank the Adventist University of the Philippines for the financial assistance provided during the conduct of the research.

\section{References}

1. Department of Health. National Tuberculosis Control Program [Online]. 2011 [cited 2014 Nov]. Available from http://www.doh.gov.ph/node/367.html .

2. Vianzon R, Garfin AM, Lagos A, Belen R. The tuberculosis profile of the Philippines, 2003-2011: advancing DOTS and beyond. Western Pac Surveill Response J. 2013; 4(2):11-6.

3. World Health Organization. Adherence to long term therapies: Evidences for action [Online]. 2003 [cited 2010 March]. Available from http://www.who.int/chp/knowledge/publications/adherence_full_report.pdf.

4. World Health Organization, Commission on Social Determinants of Health. Final Report of the Commission on Social Determinants of Health. Closing the gap in a generation: health equity through action on the social determinants of health [Online]. 2008 [cited 2014 Nov]. Available from: www.ncbi.nlm.nih.gov/pmc/articles/PMC28892973.

5. Waisbord S. Behavioral barriers in tuberculosis control: A literature review [Online]. [cited $2014 \quad$ Nov]. Available from pdf.usaid.gov/pdf_docs/Pnadf406.pdf.

6. Vermeire E, Hearnshaw H, Van Royen P, Denekens J. Patient adherence to treatment: three decades of research. A comprehensive review. J Clin Pharm Ther. 2001; 26(5):331-42.

7. Center for Disease Control. Basic TB Facts [Online]. [cited 2014 Nov]. Available from www.cdc.gov/TB/TOPIC/BASICS/default.htm.

8. Khan JA, Irfan M, Zaki A, Beg M, Hussain SF, Rizvi N. Knowledge, attitude and misconceptions regarding Tuberculosis in Pakistani patients. J Pak Med Assoc. 2006; 56(5):211-4.

9. Portero NJ, Rubio YM, Pasicatan MA. Socio-economic determinants of knowledge and attitudes about tuberculosis among the general population of Metro Manila, Philippines. Int J Tuberc Lung Dis. 2002; 6(4):301-6.

10. Muture BN, Keraka MN, Kimuu PK, Kabiru EW, Ombeka VO, Oguya F. Factors associated with default from treatment among tuberculosis patients in Nairobi province, Kenya: a case control study. BMC Public Health. 2011; 11:696.

11. Khan MA, Walley JD, Witter SN, Shah SK, Javeed S. Tuberculosis patient adherence to direct observation: results of a social study in Pakistan. Health Policy Plan. 2005; 20(6):354-65.

12. Glanz K, Rimer B, Viswanath K. Behavior and Health Education Theory, Research and Practice, $4^{\text {th }}$ ed. California: John Wiley and Sons, Inc; 2008. pp. 49-52.

13. Courtwright A. Turner AN. Tuberculosis and Stigmatization: Pathways and Interventions. Public Health Rep. 2010; 4:34-42.

14. Pachi A, Bratis D, Moussas G, Tselebis A. Psychiatric morbidity and other factors affecting treatment adherence in pulmonary tuberculosis patients. Tuber Res Treat. 2013; 2013:489865.

15. Fong C. Gender and access to DOTS (Directly Observed Treatment, Short Course) program in a poor rural and minority area of Gansu province, China. Baltimore (MD):John Hopkins University.

16. Wares D, Singh S, Acharya A, and Dangi R. Non-adherence to tuberculosis in Bali:Patient Perspectives. Quality Health Research. 2003; 7(4):327-35.

17. Green L, Mercer S. 2002. Encyclopedia of Public Health [Online]. 2002 [cited 2014 Nov]. Available from www.encyclopedia.com/doc/1G2-34000675.html. 